\title{
Does Pelletizing Catalysts Influence the Efficiency Number of Activity Measurements? Spectrochemical Engineering Considerations for an Accurate Operando Study
}

\author{
Rasmussen, Søren Birk; Perez-Ferreras, Susana; Banares, Miguel A.; Bazin, Philippe; Daturi, Marco
}

Published in:

A C S Catalysis

Link to article, DOI:

$10.1021 / \mathrm{cs} 300687 \mathrm{v}$

Publication date:

2013

Document Version

Publisher's PDF, also known as Version of record

Link back to DTU Orbit

Citation (APA):

Rasmussen, S. B., Perez-Ferreras, S., Banares, M. A., Bazin, P., \& Daturi, M. (2013). Does Pelletizing Catalysts Influence the Efficiency Number of Activity Measurements? Spectrochemical Engineering Considerations for an Accurate Operando Study. A C S Catalysis, 3(1), 86-94. https://doi.org/10.1021/cs300687v

\section{General rights}

Copyright and moral rights for the publications made accessible in the public portal are retained by the authors and/or other copyright owners and it is a condition of accessing publications that users recognise and abide by the legal requirements associated with these rights.

- Users may download and print one copy of any publication from the public portal for the purpose of private study or research.

- You may not further distribute the material or use it for any profit-making activity or commercial gain

- You may freely distribute the URL identifying the publication in the public portal 


\title{
Does Pelletizing Catalysts Influence the Efficiency Number of Activity Measurements? Spectrochemical Engineering Considerations for an Accurate Operando Study
}

\author{
Søren B. Rasmussen, ${ }^{*}, \dagger$ Susana Perez-Ferreras, ${ }^{\dagger}$ Miguel A. Bañares, ${ }^{\dagger}$ Philippe Bazin, $^{\S}$ and Marco Daturi ${ }^{\S}$ \\ ${ }^{\dagger}$ Instituto de Catálisis y Petroleoquímica (ICP), CSIC, Marie Curie 2, E-28049 Madrid, Spain \\ ${ }^{*}$ Center for Sustainable and Green Chemistry, Department of Chemistry, Technical University of Denmark, 2800 Lyngby, Denmark \\ ${ }^{\S}$ Laboratoire Catalyse et Spectrochimie, ENSICAEN, Université de Caen, CNRS, 6 Bd Maréchal Juin, F-14050 Caen, France
}

\section{Supporting Information}

\begin{abstract}
Porosity is a factor affecting catalyst efficiency in pelletized form. This implies that care should be taken with uncritically relating activity measurements from transmission operando FTIR to final catalyst performance. If the pelletizing pressure is excessive, a destruction of the pore structure of, for example, support oxides might take place, which in turn affects the pore size distribution and the porosity of the catalyst, leading to the observation of lower activity values due to decreased catalyst efficiency. This phenomenon can also apply to conventional activity measurements, in the cases that pelletizing and recrushing of samples are performed to obtain adequate particle size fractions for the catalytic bed. A case study of an operando investigation of a $\mathrm{V}_{2} \mathrm{O}_{5^{-}}$ $\mathrm{WO}_{3} / \mathrm{TiO}_{2}$-sepiolite catalyst is used as an example, and simple calculations of the influence of catalyst activity and internal pore diffusion properties are considered in this paper for the evaluation of catalyst performance in, for

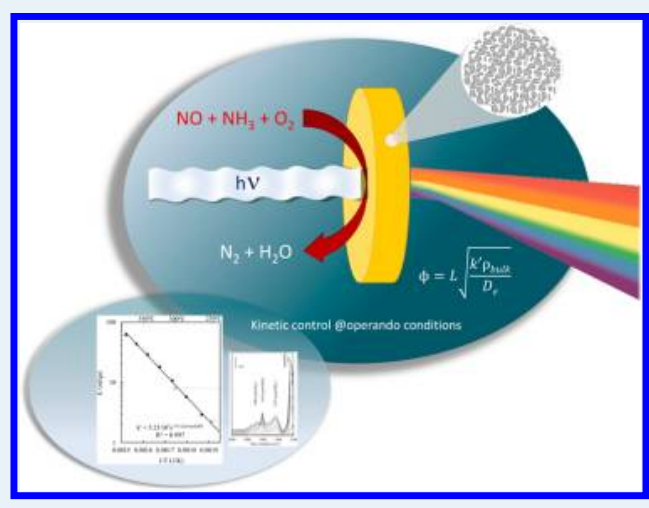
example, operando reactors. Thus, it is demonstrated that with a pelletizing pressure of $<1-2 \mathrm{ton} / \mathrm{cm}^{2}$, the pore structure is only negligibly altered, and small deteriorations of estimated catalyst efficiencies are observed for first-order kinetic constants lower than $100 \mathrm{~mL} / \mathrm{gs}$. However, if the operando study deals with highly active catalysts, it is necessary to consider efficiency losses. A simple procedure for evaluating efficiencies based on pellet dimensions and solid phase characteristics is proposed. The Thiele modulus is directly proportional to the thickness of the pellet, and, thus, inversely related to the catalyst efficiency. As a rule of thumb, we found that for catalytic constants below $100 \mathrm{~mL} / \mathrm{gs}$, the maximum thickness of the pellet pressed at 2 tons $/ \mathrm{cm}^{2} \mathrm{has}$ to be as low as $80 \mu \mathrm{m}$ to exhibit catalyst efficiencies above $90 \%$. For catalysts with $k^{\prime}=10 \mathrm{~mL} / \mathrm{gs}$, the value is $260 \mu \mathrm{m}$. This strongly underlines the importance of taking internal diffusion limitations into account when working with highly active catalysts.
\end{abstract}

KEYWORDS: operando, transmission FTIR, activity, pelletizing, porosity, efficiency

\section{INTRODUCTION}

The conceptualization of the "operando" technique shortly after the turn of the millennium facilitated an outburst of creative designs of spectroscopic cells for operando studies. ${ }^{1,2}$ Some designs were new, while some were highly inspired by, or enhancements of, pre-operando era in situ cells operating at the operando level. In recent years, an emerging interest in more reliable and well-designed operando reactors can be noted, and scientists from various spectroscopic fields have started to seriously evaluate the cell designs. In fact, in 2004, Grunwald reported a systematic approach to evaluate different reaction cells while studying the catalyst efficiency of $\mathrm{Cu}^{2+} / \mathrm{Cu}^{1+}$ over zinc oxide and $\mathrm{Pd}-\mathrm{PdO} / \mathrm{ZrO}_{2}$ systems incorporated in boron nitride or $\mathrm{Al}_{2} \mathrm{O}_{3}$ pellets for use at operando X-ray absorption spectroscopy reactors. ${ }^{3}$ These types of evaluations lie at the very heart of the operando approach, since it is implicit that, to provide reliable information, the spectroscopy is done on a real working catalyst in a well-designed kinetic experiment. However, there is a tendency that this is often neglected for natural reasons. Because of the challenges with this type of applied spectroscopy, the typical scientist using the operando approach is a spectroscopist, very often with a highly specialized background as a chemist or a physicist. This specialist will prefer to assume that the kinetic design of the reactor is sufficient and focus in detail on the spectroscopic issues, considering that the provided results in any case represent a step forward compared with the traditional "black box" reactor. However, operando technology requires complete control of both the spectroscopy and catalytic activity to provide data matching the kinetics of the process as originally proposed. ${ }^{4,5}$ Thus, cross-disciplinary efforts are highly needed for further advances in this field.

Despite their popularity, DRIFT cells suffer their intrinsic limitations, essentially due to the fact that the sample powder is

\footnotetext{
Received: October 25, 2012

Revised: November 30, 2012

Published: December 4, 2012
} 
not homogeneously heated and that only the top layer is probed by the IR beam. ${ }^{6}$ Operando cells based on transmission FTIR spectroscopy on pelletized wafered catalysts have shown high performance and continue to be one of the best compromises among band detection precision, transient behavior, and kinetic design, ${ }^{7-9}$ thanks to the quantitative asset of the spectroscopic signal in such conditions, allowing a thorough use of spectroscopic data in kinetic studies; ${ }^{10,11}$ however, some concern exists in the literature and has been manifested during conference presentations on whether the kinetic particularities present in the cell design render the acquired activity data useful ${ }^{12}$ with respect to the precision of temperature measurements, fluid dynamic properties, and the internal diffusion resistances inside the pressed pellet. In general, it should be kept in mind that using operando cells will always be a compromise between optimal spectral quality and reliable activity data. Bare and Ressler discussed these compromises with regard to XAFS spectral quality in combination with operando spectroscopy, noting that pressed wafers of the catalyst are the most uniform spectroscopically but may result in poor gas diffusion. ${ }^{13}$

A key issue of concern is the eventual compacting of the sample when pelletized into a self-supporting-or matrixincorporated-pellet. This problem is not limited only to operando cells, but constitutes an inherent problem for all researchers using compacting/pelletizing during their manipulation with catalyst samples in combination with activity measurements. Often, the oxides (e.g., zeolites, titanias, aluminas, etc.) are too fine and need to be conformed into pellets and recrushed and sieved into controlled size particles. Avery and Ramsey ${ }^{14}$ showed in one of their classic works that pressure applied to mesoporous oxides such as $\mathrm{SiO}_{2}, \mathrm{ZrO}_{2}$, and $\mathrm{TiO}_{2}$, often used as catalyst carrier materials, indeed compacts the material, yielding a lower pore volume and lower BET surface area. Alcañiz-Monge et al. reported that the compacting pressure of adsorbent materials with a high specific pore volume and specific surface area "must, undoubtedly, be taken into account" because of its important effect on textural properties. $^{15}$

Is the catalyst developer aware that he can so easily change the morphological structure of the catalyst? We choose to believe that, yes. What about being ready to run the risk of measuring activities of a catalyst distinctively different from the samples that were subjected to the characterization? Is it normal procedure to do a second check on the sample after pelletizing, to see if the surface has changed? We are almost certain that in this case, the answer is no.

The pelletizing inevitably provokes a change in the morphology and porosity of the sample. In this work, we show that this can influence the quality of, for example, the operando studies and provide some recommendations of "a window" of reliable manipulation in which this technique can be performed safely without serious damage to the value of the kinetic results. We evaluate the surface structure alterations and the pore size manipulations with $\mathrm{N}_{2}$ physisorption and mercury intrusion porosimetry (MIP). Using the pore size distribution data, we calculate the Thiele modulus to evaluate the effect of pressure as well as thickness on the pellets and compare it with recent work we have done with operando FTIR to test the concept.

\section{EXPERIMENTAL SECTION}

The catalyst sample used in this work is based on a monolithic support containing pretungstated $(10 \% \mathrm{w} / \mathrm{w})$ titania (DT-52, Millennium, particle size $<25 \mu \mathrm{m}$ ) and natural clays as binders (mainly sepiolite, Pansil 100, Tolsa S.A., Spain). A batch of monoliths was prepared by kneading the raw powders in water, containing the exact amount of needed vanadium precursor $(\beta$ $\left.\mathrm{VOSO}_{4} \cdot 5 \mathrm{H}_{2} \mathrm{O}\right)$; extruding; and subsequently drying and heattreating at $773 \mathrm{~K}$ to obtain the monolithic shaped supports with square channels, a wall thickness of $0.92 \mathrm{~mm}$, and a channel width of $1.7 \mathrm{~mm}$. The final monolith had $100 \mathrm{cpsi}$ and a geometric surface area of $991 \mathrm{~m}^{2} / \mathrm{m}^{3}$. For this study, a monolith sample was crushed to powder and pelletized by applying 2,6 , and 10 tons $/ \mathrm{cm}^{2}$ of pressure, respectively, over $40 \mathrm{mg}$ powder pressed into a dye with 0.5 in. diameter.

The $\mathrm{N}_{2}$ physisorption isotherms where performed with a Micromeritics ASAP 2420 using $\mathrm{N}_{2}$ as adsorbate at $77 \mathrm{~K}$. Samples were degassed at $1.3 \mathrm{~Pa}, 573 \mathrm{~K}$ for $16 \mathrm{~h}$ before the analysis. The distribution of specific pore volumes was calculated as follows: (i) Total micropore volume (corresponding to pores size $<0.2 \mathrm{~nm}$ ) was performed by applying $t$-plot calculations, which also allow for quantitative analysis of the external surface area and, consequently, micropore surface area. ${ }^{16-22}$ The thickness curve used for calculations was that of Harkins and Jura ${ }^{23}$ using a fitted thickness range between 3.5 and $5 \AA$. (ii) The mesoporous pore volume was determined by applying the $\mathrm{BJH}$ method to the $\mathrm{N}_{2}$ desorption data, ${ }^{24}$ and the total pore volume was determined from the amount of nitrogen adsorbed at $P / P_{0}=0.98$, assuming the molar volume to be identical to that of liquid $\mathrm{N}_{2}$ at $77 \mathrm{~K}\left(34.6 \mathrm{~cm}^{3} / \mathrm{mol}\right)$. The specific surface area was determined by using the BET (Brunauer-Emmet-Teller) equation in the interval of relative pressure range $0.05-0.3$. Pore size distributions were computed on the basis of the Kelvin equation, assuming a hemispherical meniscus (cylindrical pore model), by a method similar to that described by de Boer and co-workers. ${ }^{13}$

MIP analyses were performed with an Autopore IV 9500 equipment to determine the pore size distribution and pore volume over a range of pore diameters from $\sim 360$ to $0.003 \mu \mathrm{m}$. Around $0.120 \mathrm{~g}$ of sample was accurately weighed into the penetrometer and outgassed to a vacuum of 2.7-3.0 $\mathrm{Pa}$ at room temperature for $15 \mathrm{~min}$ before mercury-filling. The analyses were carried out up to $30000 \mathrm{psi}(200 \mathrm{MPa})$. The Washburn equation was applied to the pressure/volume data, assuming a cylindrical nonintersecting pore model and using values of $141^{\circ}$ as the contact angle of mercury and $484 \mathrm{dyn} / \mathrm{cm}$ as the surface tension. ${ }^{25}$ The primary particle sizes were determined from analyses of the intrusion curves in the interval relating to the filling of the interparticulate pore space, assuming cylindrical particle geometry. ${ }^{26}$

Standard $\mathrm{NH}_{3}-\mathrm{SCR}$ activity measurements were carried out in a fixed-bed quartz reactor, as earlier described, for the reaction: ${ }^{27,28}$

$$
4 \mathrm{NO}+4 \mathrm{NH}_{3}+\mathrm{O}_{2} \rightarrow 4 \mathrm{~N}_{2}+6 \mathrm{H}_{2} \mathrm{O}
$$

Around $50 \mathrm{mg}$ of the catalyst was loaded between two layers of inert quartz wool. The reactant gas composition for SCR was 1000 ppm NO, 1100 ppm $\mathrm{NH}_{3}, 3.5 \% \mathrm{O}_{2}, 2.7 \% \mathrm{H}_{2} \mathrm{O}$, and the balance $\mathrm{N}_{2}$. The total flow rate was maintained at $300 \mathrm{NmL} /$ min. The NO concentration was continuously monitored by a Thermo Electron model 10A rack-mounted Chemiluminescent $\mathrm{NO}-\mathrm{NO}_{x}$ gas analyzer. The catalyst activity was evaluated by 
calculating the apparent kinetic constant, $k^{\prime}$, according to the formula

$$
k^{\prime}\left(\frac{\mathrm{mL}}{\mathrm{g} \cdot \mathrm{s}}\right)=-\frac{Q}{W} \ln (1-X)=-\frac{F_{\mathrm{NO}}}{[\mathrm{NO}] W} \ln (1-X)
$$

where $F_{\mathrm{NO}}$ is the molar flow rate of NO, $Q$ is the volumetric flow rate in $\mathrm{NmL} / \mathrm{s}, W$ is the catalyst weight in grams, and $X$ is the fractional conversion.

The sample was further analyzed with an operando FTIRMS system connected to a flow setup. ${ }^{29}$ Gases were introduced into the lines (heated at $333 \mathrm{~K}$ ) by mass flow controllers. The study of the catalytic activity was followed by using timeresolved gas phase analysis by quadrupole mass spectrometry (Omnistar GSD 301 with a $1 \mathrm{~s}$ time resolution), while the species adsorbed on the material were also followed by a Thermo Scientific Nicolet 6700 FTIR spectrometer equipped with a MCT detector. The IR reactor cell, depicted in Figure 1,

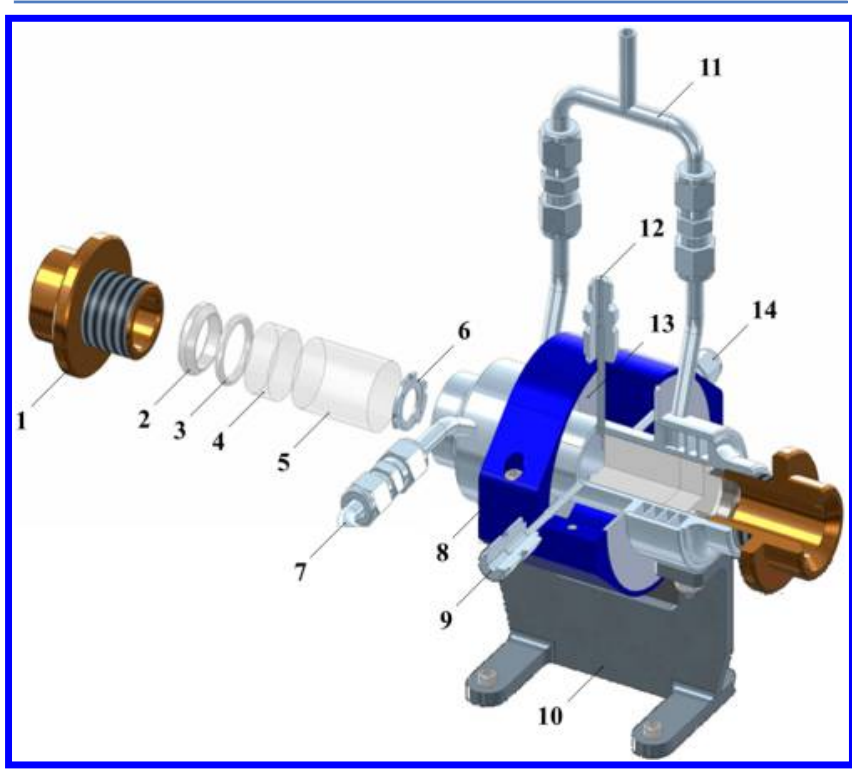

Figure 1. Exploded (left half part) and fully assembled (right half part) views of the sandwich reactor-IR cell. 1, adjusting nut for airtightness; 2, stainless steel ring; 3, Kalrez O-ring; 4, external $\mathrm{KBr}$ window; 5, internal $\mathrm{KBr}$ window; 6, wafer holder; 7, air cooling inlet; 8, external shell; 9, gas inlet; 10, IR cell support; 11, air cooling outlet; 12, thermocouple location; 13, oven location; and 14, gas outlet.

is designed to work with a pelletized catalyst and consists of a cylindrical chamber filled with IR-transparent material (mainly $\mathrm{KBr}$ ) to avoid dead space, with a thin double-ring inset that holds the catalyst pellet in shape while also allowing for feeding of reactant gas flow. The optical windows $(\mathrm{KBr})$ were kept cold by an air/water cooling system surrounding them. Inlet and outlet gas pipes complete the device.

2.2. Internal (Intraporous) Mass Transfer of Catalysts. The diffusion rate of $\mathrm{NO}$ and $\mathrm{NH}_{3}$ is greatly diminished inside the pores of a solid (e.g., pelletized) matrix. When the molecules enter the smaller pores, they diffuse more slowly, since they hit and bounce of the walls of the pores (Knudsen diffusion). In the case of sufficiently small catalyst particles, the intraporous diffusion path is short enough to allow uniform access of the reactants to all the catalyst active sites. In pellets, however, because of a much longer characteristic size, the rate of consumption of $\mathrm{NO}$ and $\mathrm{NH}_{3}$ (kinetically) can be faster than the diffusion rate of the same species inside the catalyst wall. The reactants are then used up within a thin superficial layer of catalyst, while most of the inner catalyst wall remains inactive, being depleted of reactants. The average reaction rate across the wall half-thickness is therefore lower than the reaction rate at the gas-solid interface. Details about calculations of the effective diffusion constant, by taking normal (bulk) diffusion and Knudsen diffusion into account are extensively covered elsewhere. ${ }^{30,31}$ In short, since the pellet wall can be approximated as an infinite slab just like a monolithic wall, the catalyst effectiveness factor can be described as

$$
\eta=\frac{\tan \mathrm{h} \varphi}{\varphi}
$$

where $\varphi$ is the Thiele modulus,

$$
\varphi=L \sqrt{\frac{k^{\prime} \rho_{\text {bulk }}}{D_{\mathrm{e}}}}
$$

where $L$ represents half of the depth of the monolith wall thickness, $D_{\mathrm{e}}$ is the effective intraporous diffusivity of NO, and $k^{\prime}$ is the intrinsic rate constant, as described above. More details are given in the Supporting Information.

As can be seen from eq 4 , the efficiency is dependent on the intrinsic rate constant, $k^{\prime}$. A higher $k^{\prime}$ will yield a larger Thiele modulus, which will provide a lower efficiency. The overall conversion (eq 1) depends on both, in a manner that a higher $k^{\prime}$ produces some improvement in $k_{\text {overall }}\left(\eta k^{\prime}\right)$, but not completely proportional. The effective diffusion coefficient, $D_{\mathrm{e}}$, is directly proportional to the porosity of the sample and to a certain degree related to the pore size distribution due to the Knudsen diffusion. Thus, these interrelations can be used to estimate the performance of a pelletized catalyst system by taking into account intrinsic activities, porosities, and diffusion constants.

\section{RESULTS AND DISCUSSION}

3.1. Material Properties. Figure 2 shows the $\mathrm{N}_{2}$ isotherms of the samples. The monolithic sample and the crushed but

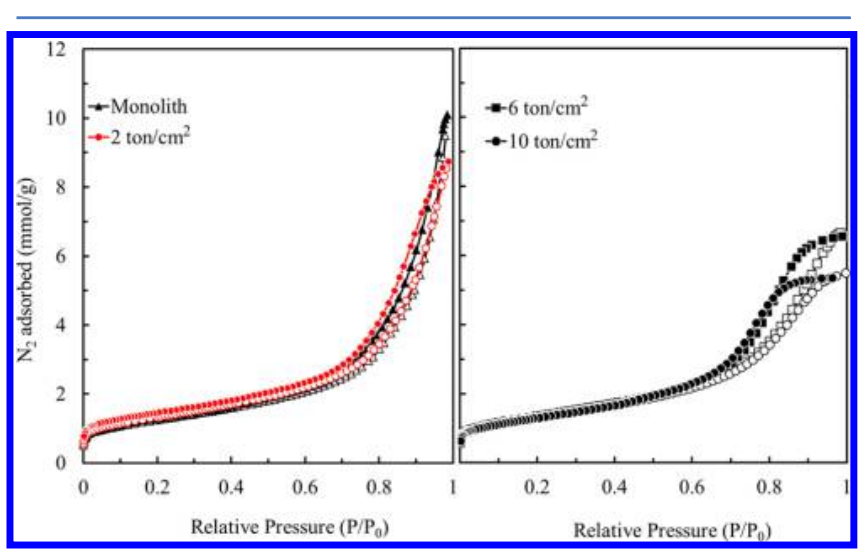

Figure 2. $\mathrm{N}_{2}$ isotherms of $\mathrm{V}_{2} \mathrm{O}_{5}-\mathrm{WO}_{3} / \mathrm{TiO}_{2}$-sepiolite catalyst samples before and after pelletizing at various pressures.

uncompacted powder (not shown for clarity reasons) show near-type II isotherms typical for a macroporous material with a heterogeneous surface. Upon compaction, the samples exhibit more features of type IV isotherms, characteristic of mesoporous solids. As the pressure of compaction was increasing, the uptake at the nitrogen saturation pressure 
decreased. The values shifted from $10.9 \mathrm{mmol} / \mathrm{g}$ for the powder to $10.2,8.7,6.7$, and $5.5 \mathrm{mmol} / \mathrm{g}$ for the monolith sample and 2,6 , and 10 ton $/ \mathrm{cm}^{2}$ compacted samples, respectively.

In parallel with the pore volume decrease, the desorption branches of the hysteresis loops moved toward lower pressures with increasing pelletizing pressure, showing that the particles have been forced sufficiently close together for the interstices to lie within the mesopore range and the pore size was decreased. This is clearly seen by the BJH analyses in Figure 3, where the

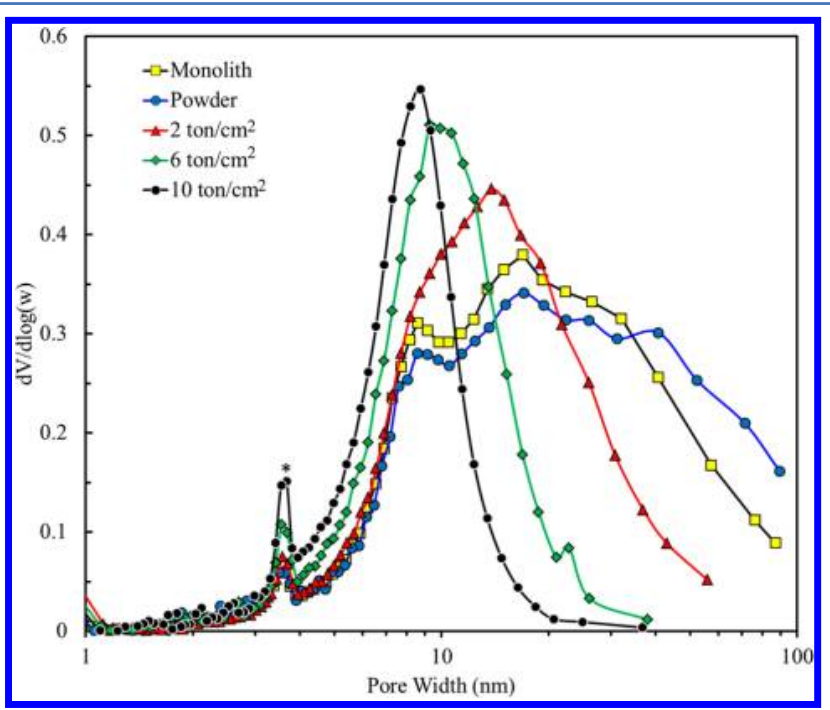

Figure 3. BJH pore size distributions from the desorption isotherms showing the generation and alteration of the mesopores.

gradual decrease of the pore size and the narrowing of the pores are evident. Values moved from $17 \mathrm{~nm}$ for the uncompacted sample and monolith to 14, 10, and $9 \mathrm{~nm}$ for samples compacted at 2,6 , and 10 ton $/ \mathrm{cm}^{2}$, respectively (see also Table $1)$. The hysteresis loop for $\mathrm{N}_{2}(77 \mathrm{~K})$ always closes at relative pressures $>0.42$. The lower closure point of hysteresis is believed to be determined by the tensile strength of the capillary condensed liquid; that is, a mechanical stability limit exists below which a macroscopic meniscus cannot exist anymore and that leads to a spontaneous evaporation of the pore liquid. This forced closure of the hysteresis leads to an artificial step in the desorption isotherm that shows the artifact at $3.5 \mathrm{~nm}$ marked with an asterisk on the graph (see Figure 3).

Contrary to the general belief, a narrow pore size distribution yields less-active catalysts, except, of course, for the special cases when shape selectivity is involved. Interestingly, by examining the low-pressure part of the isotherms in Figure 2, it seems that the small pore volumes were stable, even slightly increased, with the compaction pressure. This suggests that the pores exhibit a cylindrical shape with smaller diameter upon compacting, but compensate with longer pore lengths.
In Table 1 , the all data extracted from the $\mathrm{N}_{2}$ physisorption experiments are collated. The process of compaction involves actual adhesion of the particles of a powder to their neighbors, through the action of surface forces whenever neighboring surfaces come within atomic range of each other. The increased pressure causes a slight increase of the specific surface area for samples compacted at 2 and 6 ton $/ \mathrm{cm}^{2}$ because of the formation of mesopores, and it slightly decreases for the sample compacted at 10 ton $/ \mathrm{cm}^{2}$ because the sample changes its plasticity to a harder and more rigid structure. The tendency is the same for the external areas. This also suggests that the mesopores are generated by pressure as cylindrical shapes, yielding smaller diameters and longer pore lengths compared with the unprocessed samples.

A more direct means of comparing the shape of the isotherm of a compacted sample with that of the uncompacted (reference) powder ${ }^{32,33}$ is depicted in Figure 4. Here, the

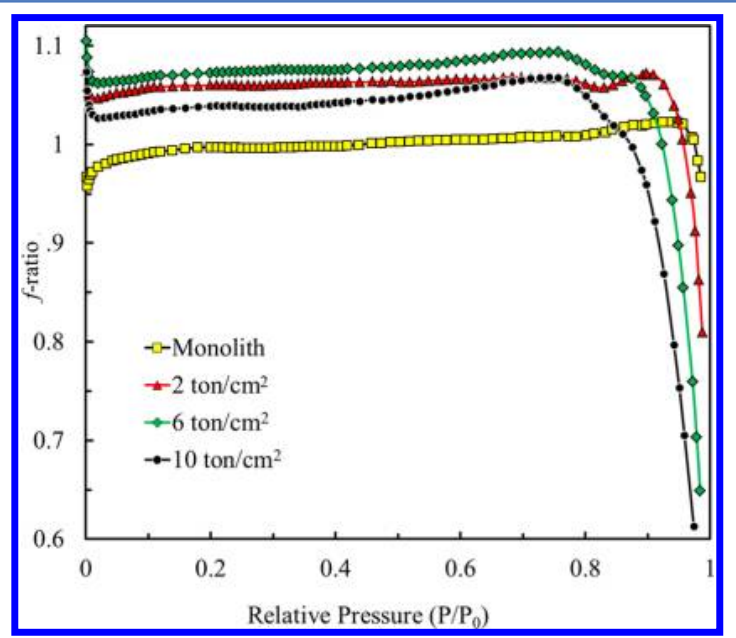

Figure 4. $f$ Plot of compacted samples using the powdered sample as reference.

ordinates of the two isotherms are read off at intervals (say 0.05 or 0.1 ) of relative pressures $P / P_{0}$, and their ratios ( $f$ ratio; where $f=n / n$ (ref), and $n$ and $n$ (ref) are adsorption on experimental material and on reference material) are calculated at each relative pressure point. Changes in the shape of the isotherm on compaction clearly show up as deviations on the $f$ plot from the horizontal tendency line. Thus, if there is no change in the isotherm, the $f$ plot will run horizontally at the level $f=1$.

The decline in $f$ plots for compacted powders $(2,6$, and 10 ton $\left./ \mathrm{cm}^{2}\right)$ at relative low pressures $\left(0.015 \mathrm{P} / \mathrm{P}_{0}\right)$, shows generation of pores with smaller pore size than for the uncompacted sample. The $f$ ratio values slightly higher than unity for the compacted samples (Figure 4) in pressure values between 0.015 and $0.87 P_{0}$ show that the uptake is increased,

Table 1. Morphological Characteristics of the Samples from $\mathrm{N}_{2}$ Physisorption Measurements

\begin{tabular}{|c|c|c|c|c|c|c|}
\hline & & powder & monolith & 2 ton $/ \mathrm{cm}^{2}$ & 6 ton $/ \mathrm{cm}^{2}$ & 10 ton $/ \mathrm{cm}^{2}$ \\
\hline \multirow[t]{3}{*}{ surface area $\left(\mathrm{m}^{2} / \mathrm{g}\right)$} & BET & 98.7 & 98.7 & 104.8 & 106.3 & 102.7 \\
\hline & micropore area & 11.2 & 9.6 & 11.1 & 10.3 & 10.1 \\
\hline & external area & 87.5 & 89.1 & 93.7 & 96.0 & 92.6 \\
\hline \multirow[t]{2}{*}{ pore volume $\left(\mathrm{cm}^{3} / \mathrm{g}\right)$} & micropore volume & 0.005 & 0.004 & 0.005 & 0.005 & 0.005 \\
\hline & BJH cumulative volume (pores $0.1-300 \mathrm{~nm}$ ) & 0.364 & 0.349 & 0.302 & 0.234 & 0.194 \\
\hline pore size distribution $(\mathrm{nm})$ & pore width & 17 & 17 & 14 & 10 & 9 \\
\hline
\end{tabular}


which implies that the specific surface areas are slightly increased. The declining slope from $\sim 0.77 P_{0}$ for the compacted samples and at $0.96 P_{0}$ for the monolith shows that the relative nitrogen uptake is less than for the uncompacted sample at high relative pressures, which is due to the pore volume decrease from the pelletizing process. Obviously, the small variations in the graph are due to the superficial similarity between the sample used as reference and the monolith.

The MIP curves corresponding to the powdered, monolithic, and pelletized samples are represented in Figure 5. The powder

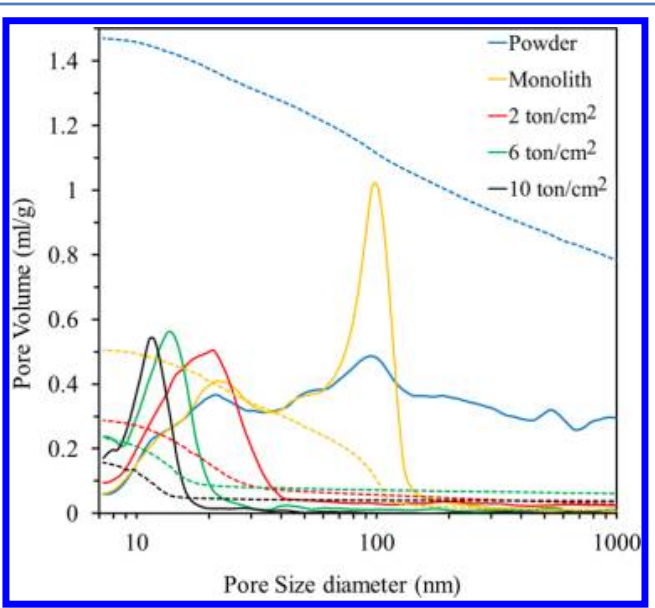

Figure 5. Pore size distribution (line) and cumulative volume (dotted line) for uncompacted and compacted materials.

sample shows a poorly defined pore size distribution (PSD) with three main peaks. The first one was located at $23 \mathrm{~nm}$ because of intraparticulate porosity; the second one, at $100 \mathrm{~nm}$ as a result of interparticulate porosity; and the third one, at $3000 \mathrm{~nm}$, outside the range of Figure 5, which is the point where the mercury intrudes between the agglomerated particles.

The PSD of the monolithic sample exhibits the characteristics of a conformed material, with a bimodal curve due to contributions from both intra- and interparticulate porosities, which may be distinguished by the minimum at $36 \mathrm{~nm}$. Pelletizing at 2 tons $/ \mathrm{cm}^{2}$ causes the resolution between intraparticulate and interparticulate porosities to become unclear, now with a maximum at $21 \mathrm{~nm}$ and a small shoulder included at $15 \mathrm{~nm}$. Pelletizing at 6 and 10 tons $/ \mathrm{cm}^{2}$ yields a displacement to smaller pore size diameters to 14 and $12 \mathrm{~nm}$, respectively. As a general observation, after pelletizing of the sample, all pores become mesopores with diameters $<50 \mathrm{~nm}$. These results are in good agreement with those obtained from the BJH method. Total pore areas calculated from MIP analyses presented in Table 2 were calculated using a cylindrical nonintersecting pore model and represent only the surface area of pores down to $3.5 \mathrm{~nm}$ pore radius.

Discrepancies between surface area values obtained from this method and nitrogen physisorption are due to the presence of pores with $<3.5 \mathrm{~nm}$ radii, which are undetected by MIP. When raw materials are compacted from the minimum pressure (monolith) to the maximum $\left(10 \mathrm{ton} / \mathrm{cm}^{2}\right)$, the interparticle porosity disappears. As a consequence, the total pore volume has been reduced dramatically because of the pressure effect (Figure 5 and Table 2). This reduction is $66 \%$ for the monolith sample, $80 \%$ for 2 ton $/ \mathrm{cm}^{2}, 83 \%$ for 6 ton $/ \mathrm{cm}^{2}$, and $89 \%$ for 10
Table 2. Morphological Characteristics of the Samples from MIP Measurements

\begin{tabular}{lccccc} 
& powder & monolith & $\begin{array}{c}2 \text { ton/ } \\
\mathrm{cm}^{2}\end{array}$ & $\begin{array}{c}6 \text { ton/ } \\
\mathrm{cm}^{2}\end{array}$ & $\begin{array}{c}10 \text { ton/ } \\
\mathrm{cm}^{2}\end{array}$ \\
$\begin{array}{l}\text { total intrusion volume } \\
(\mathrm{mL} / \mathrm{g})\end{array}$ & 1.47 & 0.51 & 0.29 & 0.24 & 0.16 \\
$\begin{array}{c}\mathrm{MIP} \text { total pore area } \\
\left(\mathrm{m}^{2} / \mathrm{g}\right)\end{array}$ & 59 & 60 & 55 & 52 & 41 \\
$\begin{array}{c}\mathrm{MIP} \text { bulk density } \\
(\mathrm{g} / \mathrm{mL})\end{array}$ & 0.52 & 1.16 & 1.22 & 1.50 & 1.66 \\
$\%$ porosity & 77 & 59 & 35 & 36 & 26 \\
\hline
\end{tabular}

tons $/ \mathrm{cm}^{2}$. This decrease is in agreement with the $\mathrm{N}_{2}$ physisorption results given in Table 1 .

The MIP bulk densities increased up to a factor of 3 for the pellets as a result of the porosity decrease. By the MIP method, bulk density is calculated from the mass of particles composing the bed divided by the bulk volume of the bed. This volume includes all pores, open and closed, and interstitial space between particles. As a consequence, the loss of interstitial space due to compaction reduces bulk volume and increases bulk density values.

In Figure 6, the activities of the catalyst are given as an Arrhenius relation. For comparison, a standard $\mathrm{V}_{2} \mathrm{O}_{5}-\mathrm{WO}_{3}$ /

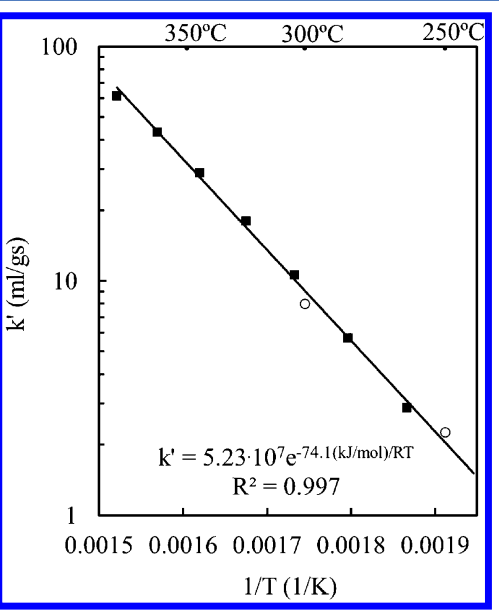

Figure 6. Arrhenius relation of activities versus inverse temperatures. Solid squares are data points from the conventional microreactor; the open circles are from the operando FTIR sandwich cell reactor.

$\mathrm{TiO}_{2}$ catalyst similar to industrial catalysts exhibits an apparent kinetic constant up to around $k^{\prime}=1000 \mathrm{~mL} / \mathrm{gs} .{ }^{34}$ Considering that the sample under study contains $50 \%(\mathrm{w} / \mathrm{w})$ of binder material, it appears that it has 5 times lower activity on the basis of the amount of the active phase, probably due to some deactivation by cationic contaminants present in the binder material. This doesn't affect the purpose of this study, since we here aim to compare observed specific activities from a conventional microreactor rig and an operando reactor. As can be seen in Figure 6, with the open circles, the activity points measured with the operando reactor lie satisfactorily close to the microreactor activities. It has to be mentioned that the temperature of the operando reactor was calibrated earlier, and the points given here are with a maximum temperature gradient of $14 \mathrm{~K}$ from the thermocouple measuring point, inserted in the pellet holder and touching the border of the actual pellet.

3.2. Operando Study. In Figures 7 and 8, the FTIR spectra from the operando FTIR-MS study are given. The spectrum of 


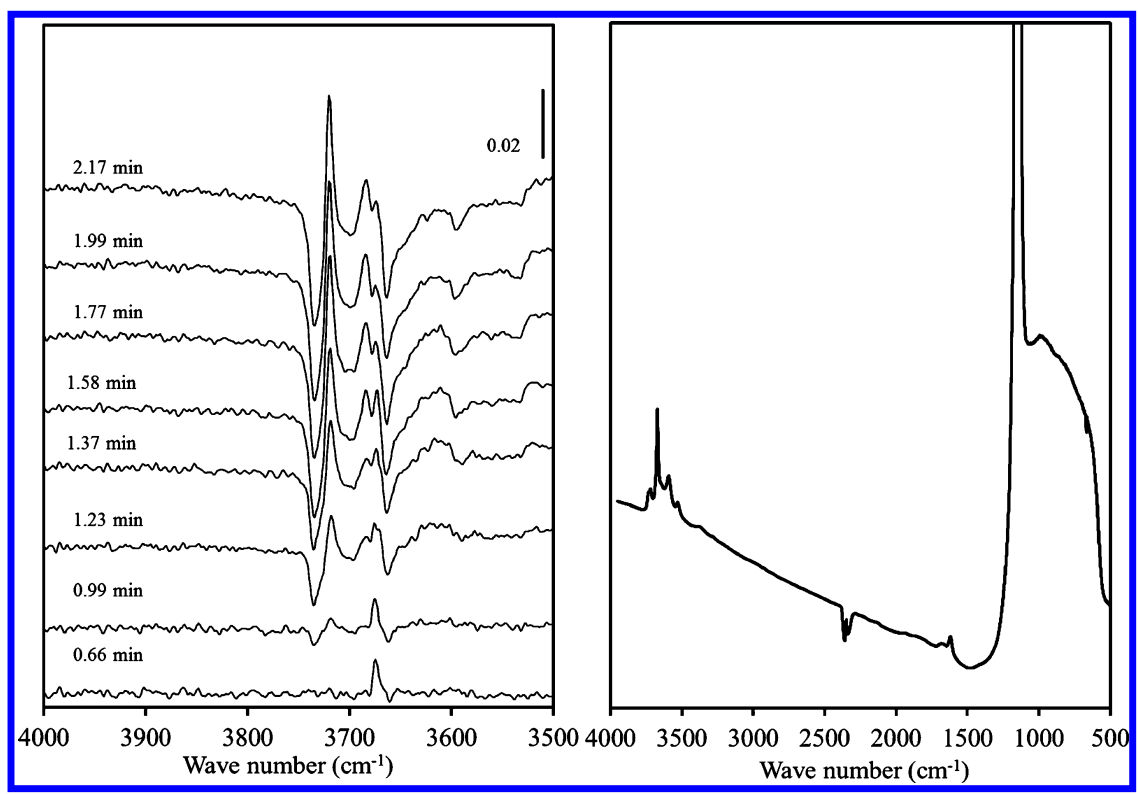

Figure 7. Operando FTIR spectra. Right: base spectrum of oxidized catalyst at $523 \mathrm{~K}$. Left: difference spectra, after changing the gas phase to 1000 ppm $\mathrm{NH}_{3} / \mathrm{Ar}$, in the $3500-4000 \mathrm{~cm}^{-1}$ range.

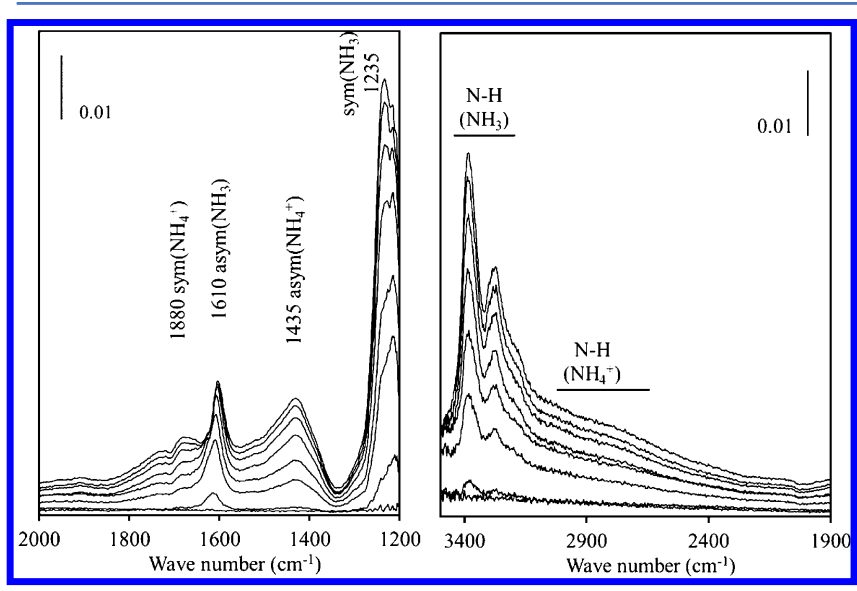

Figure 8. Operando FTIR spectra. Left: difference spectra, after changing the gas phase to $1000 \mathrm{ppm} \mathrm{NH}_{3} / \mathrm{Ar}$, in the $2000-1200 \mathrm{~cm}^{-1}$ range. Right: the $3500-1900 \mathrm{~cm}^{-1}$ range.

the catalyst treated under an $\mathrm{Ar}+\mathrm{O}_{2}$ flow at $523 \mathrm{~K}$ is presented in Figure 7, right part. It shows a cutoff below $1300 \mathrm{~cm}^{-1}$ due to the presence of silicates in the binder. This also affects the $\nu(\mathrm{OH})$ stretching region, engendering a complex hydroxyl massif, which cannot be unambiguously interpreted: the features of silanols are present at 3742 and $3530 \mathrm{~cm}^{-1}$, whereas anatase hydroxyls can be ascribed to the bands at 3720 and $3673 \mathrm{~cm}^{-1} ; 36,37$ the shoulder at $3686 \mathrm{~cm}^{-1}$ and the band at $3647 \mathrm{~cm}^{-1}$ could be assigned to $\mathrm{V}-\mathrm{OH}$ species, ${ }^{38,39}$ together with the peak at $3593 \mathrm{~cm}^{-1}$, ${ }^{40}$ whereas adsorbed water is visible at 3384 and $1620 \mathrm{~cm}^{-1}$. Alternatively, the bands at 3686 and $3647 \mathrm{~cm}^{-1}$ can be assigned to $\mathrm{W}-\mathrm{OH}$, as reported by Reiche et al. in their studies of vanadia over rutilized titania. ${ }^{40}$ The weak bands between 2200 and $1700 \mathrm{~cm}^{-1}$ are due to overtones and combination bands. ${ }^{41}$ Upon ammonia introduction in the flow, we observe a perturbation of the band assigned to $\mathrm{Ti}-\mathrm{OH}$ at $3720 \mathrm{~cm}^{-1}$ shifting toward lower frequencies, probably because of ammonia adsorption on a neighboring site. In addition, the band near $3670 \mathrm{~cm}^{-1}$ undertakes a progressive decrease while a sharp band grows at $\sim 3680 \mathrm{~cm}^{-1}$, rapidly reaching a steady state, accompanied by another peak at higher wavenumbers $\left(\sim 3690 \mathrm{~cm}^{-1}\right)$, which continue to increase. This might be justified by a shift of the $\mathrm{OH}$ groups toward $\mathrm{W}$ sites, as soon as vanadium sites are occupied by ammonia, as suggested by the progressive decrease of the band below $3600 \mathrm{~cm}^{-1}$. In parallel, additional features of ammonium and coordinated ammonia are observed at lower wavenumbers (Figure 8): the asymmetric deformation of ammonia adsorbed on Lewis acid sites is detected at $1610 \mathrm{~cm}^{-1}$, the symmetric components being at $1235 \mathrm{~cm}^{-1}$. ${ }^{42}$ The presence of shoulders suggests the existence of multiple sites, as observed in the $\nu(\mathrm{OH})$ region. Ammonium ions give rise to broad bands at 1680 and $1435 \mathrm{~cm}^{-1}{ }^{34}$ The corresponding $\nu(\mathrm{NH})$ bands are visible in the $3500-2500 \mathrm{~cm}^{-1}$ region.

Looking at band profiles (Figures 8 and 9), it seems that ammonia adsorption takes place before ammonium formation, indicating a sequence in the reaction mechanism. The evolution of the band at $3675 \mathrm{~cm}^{-1}$ could indicate that ammonia is first

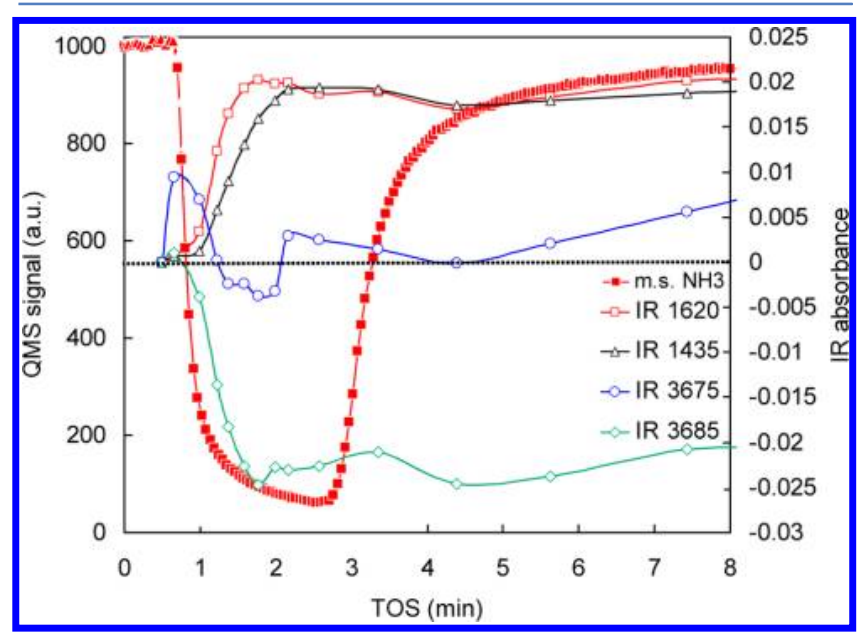

Figure 9. Selected mass traces and chemigrams from the operando FTIR-MS study during step exposure of $\mathrm{NH}_{3}+\mathrm{O}_{2}$ to an oxidized catalyst. 
adsorbed on $\mathrm{Ti}$ sites, then transformed into ammonium (on a $\mathrm{V}$ or $\mathrm{W}$ site), which reacts on its turn. These details are relevant in the description of the SCR reaction mechanism and show well the intrigue of the operando approach, but are out of the purpose of the present paper and will be described in detail elsewhere.

Figure 10 plots the computed catalyst efficiencies, taking all changes in porosities, pore width, Knudsen diffusion, character-

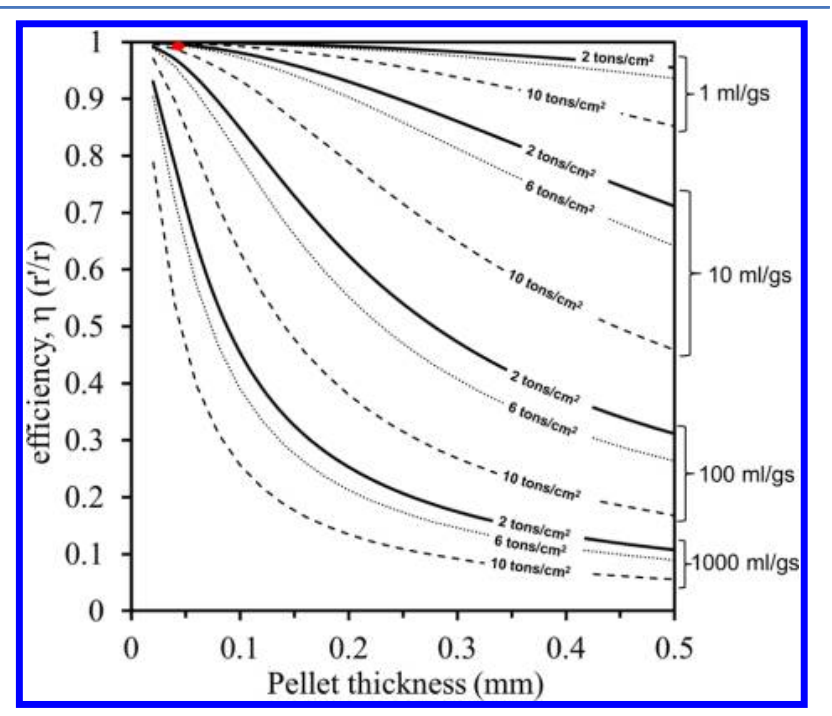

Figure 10. Pellet efficiencies as a function of pellet thickness and intrinsic activity for the 2,6 , and 10 tons $/ \mathrm{cm}^{2}$ applied pressures during the pelletizing procedure. Red dot in the top left graphic is the conditions applied in our case study.

istic wall length, intrinsic activities, etc. into account. Thus, Figure 10 shows the calculated efficiencies of catalyst pellets after pelletizing at $0.8,2,6$, and 10 tons $/ \mathrm{cm}^{2}$. The values are obtained by taking the changes in the pore structure into account, which decrease the pore volume and leave only mesopores in the pelletized material. For each material, the efficiency number has been calculated for various values of the intrinsic activity constant, $k^{\prime}$, in the range $0-1000 \mathrm{~mL} / \mathrm{gs}$. Normally, a pellet for transmission FTIR measurements will be around $100-400 \mu \mathrm{m}(0.1-0.4 \mathrm{~mm})$ to achieve sufficient matter for the conformation while allowing sufficient transparency of the pellet. As can be seen, the thickness of the material highly affects the efficiency number, but it is also seen that a significant increase in the $k^{\prime}$ value highly affects the observed efficiency number already for very thin pellets.

This effect is even more pronounced when higher pressures of pelletizing are used. For the high pressures near 10 tons $/ \mathrm{cm}^{2}$, it is necessary to achieve a pellet size of only $40 \mu \mathrm{m}$ to have efficiency numbers higher than $90 \%$ during the measurements with a $k^{\prime}=100 \mathrm{~mL} / \mathrm{gs}$. This is noteworthy and relevant not only for transmission FTIR measurements but also for general activity measurements of catalysts. When using the widely used method of pelletizing, crushing, and sieving a catalyst sample, the same modifications will take place. Assuming spherical particles, the characteristic length will be $r / 3$, which will somewhat diminish the problem, but still, when working with highly active samples $\left(k^{\prime}\right.$ values for the $\mathrm{NH}_{3}-\mathrm{SCR}$ reaction can sometimes be as high as $<2000 \mathrm{~mL} / \mathrm{gs}),{ }^{43}$ this manipulation could certainly become an issue. Although it should be obvious, here, all scientists should be warned to take good care and explain to students the importance of using pressures as low as possible when creating sieved fractions of highly active catalysts such as, for example, $\mathrm{V}_{2} \mathrm{O}_{5} / \mathrm{TiO}_{2},{ }^{35} \mathrm{Cu}$-zeolites, ${ }^{44}$ etc.

For the operando studies using pellets, it might be impossible in most cases to achieve sufficiently high efficiency numbers to render this effect negligible. We would instead recommend that activity measurements be performed in parallel with the operando measurements such that a reasonable idea of the internal diffusion effects might be clear. It is, however, especially important not to use catalyst activity as a direct way to internally calibrate the temperature gradient of an operando reactor. Imagine the (likely) situation in which a highly active catalyst is used as a testing probe, where activity measurements are compared between powder and pellet measurements. Because of the low efficiency, which could be near $75 \%$ in the case of around $1000 \mathrm{~mL} / \mathrm{gs}$ using $1-2$ tons $/ \mathrm{cm}^{2}$ for a 40 $\mu \mathrm{m}$ pellet, a lower apparent activity will be observed in the operando reactor. The obvious but wrong action would then be to overcompensate the value of the temperature gradient. This would certainly lead to retrieval of spurious kinetic parameters during the operando study. Only by controlling the effect of pelletizing is a correct calibration of the operando reactor possible.

A few general "rules of thumb" can be extracted as examples from Figure 10. For catalytic constants below $100 \mathrm{~mL} / \mathrm{gs}$, the maximum thickness of the pellet pressed at 2 tons $/ \mathrm{cm}^{2}$ has to be as low as $50 \mu \mathrm{m}$ to exhibit catalyst efficiencies above $90 \%$. For catalysts with $10 \mathrm{~mL} / \mathrm{gs}$, the value is $180 \mu \mathrm{m}$. In our case study, we were working with a catalyst with a $k^{\prime}=7 \mathrm{~mL} / \mathrm{gs}$ at $300{ }^{\circ} \mathrm{C}$ with a thickness around $60 \mu \mathrm{m}$, which exhibited a high efficiency constant, above $98 \%$.

3.3. General Discussion and Recommendations. It is obvious from the results above that great care has to be taken while evaluating the activities of a pelletized catalyst. In this work, we report extensively on the influence of the pore structure. In our case, using titanium oxide mixed with clay, we observed a nearly complete collapse of the interparticle macropore structure and a decrease in the size of the mesopores. This is likely to occur similarly for other oxidebased catalyst supports, such as $\mathrm{Al}_{2} \mathrm{O}_{3}, \mathrm{ZrO}_{2}$, hierarchical zeolites (due to the change of the mesopore structure), etc. Probably few operando laboratories will have access to mercury intrusion porosimetry, but because of the mentioned collapse, it will probably be reasonable to conclude that no macroporosity will be present in the sample. Thus, a conventional $\mathrm{N}_{2}$ physisorption measurement applying the $\mathrm{BJH}$ method to achieve the pore size, combined with noting the total pore volume (in terms of liquid $\mathrm{N}_{2}$ adsorbed at $P / P_{0}=0.98$ ) will be sufficient to calculate the effective diffusion coefficient in the Knudsen regime and, thus, obtain the Thiele modulus for the efficiency calculations.

\subsection{CONCLUSIONS}

The precise control of catalytic activities in combination with in situ and operando spectroscopic studies is of utmost importance. The optimal solution considering both spectral acquisition and reactor design is always sought. In the specific case of transmission FTIR spectroscopy (which is spectroscopically to be preferred with respect to DRIFT to catch reliable qualitative and quantitative data) some extra considerations are needed because of the effect of pelletizing. This work illustrates with an $\mathrm{NH}_{3}-\mathrm{SCR}$ catalyst that a system can be studied with respect to internal diffusion resistance effects, and complete control of the effect of wafering can be achieved only with the 
use of $\mathrm{N}_{2}$ physisorption and parallel activity measurements. However, this work also concludes that the pelletizing effects of oxide-based catalysts $\left(\mathrm{TiO}_{2}-\right.$ sepiolite, in this specific case) forces a complete collapse of the macropores and, thus, leads to significantly lower porosities compared with uncompressed powders. This implies that care should be taken with noncritically related activity measurements from transmission operando FTIR to final catalyst performance, especially when studying highly active catalysts. If the pelletizing pressure is excessive, a destruction of the pore structure of, for example, support oxides might take place, which in turn affects the pore size distribution and the porosity of the catalyst. This phenomenon can also apply to conventional activity measurements, in the cases that pelletizing and recrushing of samples are performed to obtain adequate particle size fractions for the catalytic bed. This case study of an operando investigation of a $\mathrm{V}_{2} \mathrm{O}_{5} \mathrm{WO}_{3} / \mathrm{TiO}_{2}$-sepiolite catalyst shows that simple calculations of the influence of catalyst activity and internal pore diffusion properties can take these issues into account.

It is also demonstrated that with a pelletizing pressure of less than $1 \mathrm{ton} / \mathrm{cm}^{2}$ (currently used by the authors in their laboratories), the pore structure is only negligibly altered, and little change in estimated catalyst efficiencies are observed for first-order kinetic constants lower than $100 \mathrm{~mL} / \mathrm{gs}$. In such a case, operando results are highly reliable and representative of a real process, and the transmission IR reactor-cell used in this study is able to generate relevant data for a correct kinetic interpretation of the reaction. If an operando study deals with more active catalysts, efficiency losses have to be taken into consideration. Here, we propose a simple procedure for evaluating efficiencies on the basis of pellet dimensions and solid phase characteristics.

\section{ASSOCIATED CONTENT}

\section{(S) Supporting Information}

Powder X-ray diffractograms of samples after pelletizing and calculations of efficiency numbers. This material is available free of charge via the Internet at http://pubs.acs.org.

\section{AUTHOR INFORMATION}

\section{Corresponding Author}

*E-mails: sbrasmussen@icp.csic.es (ICP), sbra@kemi.dtu.dk (Technical University of Denmark).

\section{Notes}

The authors declare no competing financial interest.

\section{ACKNOWLEDGMENTS}

J. D. Grünwaldt is thanked for discussions; Johannes DueHansen, for performing the powder activity measurement. This collaborative work was supported by the bilateral CSIC-CNRS project 2009FR0023. Support from the Spanish Ministry of Science and Innovation (CTQ2008-04361/PPQ, CTQ201125517, CTM2008-06876-CO2-02/TECNO), JAE (Junta de Ampliación de Estudios), DONG Energy A/S, Energinet.dk and their PSO funds (Projects FU5201, FU7318), and Unidad de Apoyo from Catalysis Institute (ICP-CSIC) are acknowledged.

\section{REFERENCES}

(1) Weckhuysen, B. M. (Ed.) In situ Spectroscopy of Catalysts, American Scientific Publishers: Stevenson Ranch, CA, 2004.

(2) Weckhuysen, B. M. Phys. Chem. Chem. Phys. 2003, 5 (20), 4351.
(3) Grunwaldt, J.-D.; Caravati, M.; Hannemann, S.; Baiker, A. Phys. Chem. Chem. Phys. 2004, 6, 3037.

(4) Guerrero-Pérez, M. O.; Bañares, M. A. Chem. Commun. 2002, 1292.

(5) Bañares, M. A.; Guerrero-Pérez, M. O.; Fierro, J. L. G.; Cortez, G. G. J. Mater. Chem. 2002, 12, 3337.

(6) Mondelli, C.; Dal Santo, V.; Trovarelli, A.; Boaro, M.; Fusi, A.; Psaro, R.; Recchia, S. Catal. Today 2006, 113, 81.

(7) Vimont, A.; Thibault-Starzyk, F.; Daturi, M. Chem. Soc. Rev. 2010, 39, 4928.

(8) Wuttke, S.; Bazin, P.; Vimont, A.; Serre, C.; Seo, Y.-K.; Hwang, Y. K.; Chang, J.-S.; Férey, G.; Daturi, M. Chem.-Eur. J. 2012, 18, 11959.

(9) Bobadilla, L. F.; Marie, O.; Bazin, P.; Daturi, M. Catal. Today 2012, Operando IV special issue, in press, dx.doi.org/10.1016/ j.cattod.2012.08.019.

(10) Lietti, L.; Daturi, M.; Blasin-Aubé, V.; Ghiotti, G.; Prinetto, F.; Forzatti, P. ChemCatChem 2012, 4, 55.

(11) Bazin, P.; Thomas, S.; Marie, O.; Daturi, M. Catal. Today 2012, $182,3$.

(12) Meunier, F. Chem. Soc. Rev. 2010, 39, 4602.

(13) Bare, S. R.; Ressler, T. Adv. Catal. 2009, 52, 339.

(14) Avery, R. G.; Ramsey, J. D. F. J. Colloid Interface Sci. 1973, 42, 3.

(15) Alcañiz-Monge, J.; Trautwein, G.; Pérez-Cadenas, M.; RománMartínez, M. C. Microporous Mesoporous Mater. 2009, 126, 291.

(16) Lippens, B. C.; Linsen, B. G.; de Boer, J. H. J. Catal. 1964, 3, 32.

(17) de Boer, J. H.; Lippens, B. C. J. Catal. 1964, 3, 38.

(18) Lippens, B. C.; de Boer, J. H. J. Catal. 1964, 3, 44.

(19) de Boer, J. H.; Linsen, B. G.; Osinga, Th.J. J. Catal. 1965, 4, 643.

(20) de Boer, J. H.; Linsen, B. G.; van der Plas, Th.; Zondervan, G. J.

J. Catal. 1965, 4, 649.

(21) Lippens, B. C.; de Boer, J. H. J. Catal. 1965, 4, 319.

(22) Cranston, R.; Inkley, F. Adv. Catal. 1957, 9, 143.

(23) Harkins, W. D.; Jura, G. J. Chem. Phys. 1943, 11, 431.

(24) Barrett, E. P.; Joyner, L. S.; Halenda, P. P. J. Am. Chem. Soc. 1951, 73, 373.

(25) Washburn, E. W. Proc. Natl. Acad. Sci. U.S.A. 1921, 7, 115.

(26) Mayer, R. P.; Stowe, R. A. J. Colloid Interface Sci. 1965, $20,893$.

(27) Due-Hansen, J.; Rasmussen, S. B.; Mikolajska, E.; Bañares, M. A.; Ávila, P.; Fehrmann, R. Appl. Catal., B 2011, 107, 340.

(28) Rasmussen, S. B.; Bañares, M. A.; Bazin, P.; Due-Hansen, J.; Ávila, P.; Daturi, M. Phys. Chem. Chem. Phys. 2012, 14, 2171.

(29) Lesage, T.; Verrier, C.; Bazin, P.; Saussey, J.; Daturi, M. Phys. Chem. Chem. Phys. 2003, 5, 4435.

(30) Tronconi, E.; Beretta, A. Catal. Today 1999, 52, 249.

(31) Beeckman, J. W.; Hegedus, L. L. Ind. Eng. Chem. Res. 1991, 30, 969.

(32) Gregg, S. J. J. Chem. Soc., Chem. Commun. 1975, 699.

(33) Gregg, J.; Langford, J. F. J. Chem. Soc., Faraday Trans. 1 1977, 73, 747.

(34) Due-Hansen, J.; Kustov, A. L.; Rasmussen, S. B.; Fehrmann, R.; Christensen, C. H. Appl. Catal., B 2006, 66, 161.

(35) Gallas, J.-P.; Goupil, J.-M.; Vimont, A.; Lavalley, J.-C.; Gil, B.; Gilson, J.-P.; Miserque, O. Langmuir 2009, 25, 5825.

(36) Busca, G.; Saussey, H.; Saur, O.; Lavalley, J.-C.; Lorenzelli, V. Appl. Catal. 1985, 14, 245.

(37) Kantcheva, M.; Davydov, A.; Hadjiivanov, K. J. Mol. Catal. 1993, 81, L25.

(38) Busca, G.; Ramis, G.; Lorenzelli, V. J. Mol. Catal. 1989, 50, 231.

(39) Kantcheva, M. M.; Hadjiivanov, K. I.; Klissurski, D. G. J. Catal. 1992, 134, 299.

(40) Reiche, M. A.; Bürgi, T.; Baiker, A.; Scholz, A.; Schnyder, B.; Wokaun, A. Appl. Catal., A 2000, 198, 155.

(41) Martin, C.; Rives, V.; Sanchez-Escribano, V.; Busca, G.; Lorenzelli, V.; Ramis, G. Surf. Sci. 1991, 251/252, 825.

(42) Lietti, L.; Alemany, J. L.; Forzatti, P.; Busca, G.; Ramis, G.; Giamello, E.; Bregani, F. Catal. Today 1996, 29, 143.

(43) Kristensen, S. B.; Kunov-Kruse, A. J.; Riisager, A.; Rasmussen, S. B.; Fehrmann, R. J. Catal. 2011, 275, 60. 
(44) Kwak, J. H.; Tonkyn, R. G.; Kim, D. H.; Szanyi, J.; Peden, C. H.

F. J. Catal. 2010, 275, 187. 